\title{
FUNCTIONAL OUTCOME OF PLATING IN PROXIMAL TIBIA FRACTURES USING MINIMALLY INVASIVE PERCUTANEOUS PLATE OSTEOSYNTHESIS
}

\author{
Pradeep Kumar Verma ${ }^{1}$, Prateek Ahlawat2, Hari Babu Meena ${ }^{3}$,Kumar Rohit ${ }^{4}$, P. K. Lakhtakia ${ }^{5}$ \\ ${ }^{1}$ Assistant Professor, Department of Orthopaedics, SGMH, Rewa. \\ 2 Postgraduate Student, Department of Orthopaedics, SGMH, Rewa. \\ ${ }^{3}$ Postgraduate Student, Department of Orthopaedics, SGMH, Rewa. \\ 4 Postgraduate Student, Department of Orthopaedics, SGMH, Rewa. \\ 5 Professor and HOD, Department of Orthopaedics, SGMH, Rewa.
}

ABSTRACT

\section{BACKGROUND}

Management of proximal tibial fractures has always been controversial. The main aim in management of such fractures is to achieve articular congruity, proper limb alignment and proper joint mobility besides achieving union. ORIF using either single or dual plates has been in vogue for long time with good outcomes. But these are associated with problems, especially overlying skin conditions, delayed recovery and rehabilitation with limited functional outcome. To overcome these problems, MIPPO technique has been devised which is based on principle of indirect reduction without opening the fracture site. It involves lesser incision, lesser soft tissue dissection with lesser complications and better functional outcomes.

\section{MATERIALS AND METHODS}

The present study was carried out on the patients admitted in orthopaedic ward of Shyam Shah Medical College and associated Sanjay Gandhi Memorial Hospital, Rewa (M.P.) during the 2-year period from October 2013 to September 2015. The fractures were assessed for soft tissue injuries and followed by radiological assessment of fracture with Schatzker's classification. All patients included in the study group were given an "inverted hockey stick incision" followed by MIPPO. All patients were followed up regularly at an average of 6 - 8 weeks till fracture union was complete. A clinical and radiological evaluation was carried out using the modified Rasmussen clinical and radiological criteria.

\section{RESULTS}

Out of the 40 patients treated, most of them were males and belonged to the age group of 20 - 40 years (75\%). Unilateral fractures were more common than bilateral fractures and were of the type 3 and type 4 of Schatzker's classification associated with high velocity RTA. Infection, implant failure and non-union were reported in 3 patients one in each; 23 fractures gave excellent result; 12 fractures healed with good results. Only 3 of the patients showed fair results and 2 had poor result.

\section{CONCLUSION}

All the fractures treated with MIPPO technique were found to be rapidly healing by secondary fracture union and hence achieving strong bone union across the fracture site due to inherent benefits of less tissue damage and minimal disturbance of fracture site biology.

\section{KEYWORDS}

Proximal Tibial Fractures, MIPPO, Functional Outcome.

HOW TO CITE THIS ARTICLE: Verma PK, Ahlawat P, Meena HB, et al. Functional outcome of plating in proximal tibia fractures using minimally invasive percutaneous plate osteosynthesis. J. Evolution Med. Dent. Sci. 2017;6(21):1725-1730, DOI: $10.14260 /$ Jemds/2017/379

\section{BACKGROUND \\ Tibial plateau fractures occur when proximal tibia experiences an excessive axial load. The mechanism of injury and the energy required to cause these fractures are age dependent. Younger patients tend to sustain these fractures secondary to high energy trauma such as fall from height and motor vehicle accidents, while older patients sustain these fractures secondary to low energy trauma such as low level fall or stumble.}

Financial or Other, Competing Interest: None

Submission 16-02-2017, Peer Review 04-03-2017,

Acceptance 07-03-2017, Published 13-03-2017.

Corresponding Author:

Dr. Pradeep Kumar Verma,

\#F12/1, New Doctors' Colony,

Arjun Nagar, Rewa.

E-mail: drpkverma1228@gmail.com

DOI: $10.14260 /$ jemds $/ 2017 / 379$
The management of these types of injuries has for long been subject of controversy. The spectrum of treatment ranges from simple casting and bracing to skeletal traction and early motion to open reduction and internal fixation..$^{1,2}$

With the better understanding of fracture healing biology and biomechanics of fracture fixation and healing, the current trend of treatment is towards biological fixation, which can be accomplished by MIPPO technique. Percutaneous fixation offers its best in isolated undisplaced fractures, split unicondylar fractures and in elderly osteoporotic bone.

The advantages are decreased operative time, less blood loss, smaller incision, short hospital stay and early rehabilitation. ${ }^{3}$

\section{Objectives}

To find out the functional outcome of proximal tibial fractures treated with locking compression plate by minimally invasive percutaneous osteosynthesis technique (MIPPO). 


\section{MATERIALS AND METHODS \\ Source of Data}

The present study was carried out on the patients admitted in orthopaedic ward of Shyam Shah Medical College and associated Sanjay Gandhi Memorial Hospital, Rewa (M.P.) during the 2-year period from October 2013 to September 2015. The fractures were assessed for soft tissue injuries and followed by radiological assessment of fracture with Schatzker's classification. All patients included in the study group were given an "inverted hockey stick incision" followed by MIPPO. All patients were followed up regularly at an average of 6 - 8 weeks till fracture union was complete. A clinical and radiological evaluation was carried out using the modified Rasmussen clinical and radiological criteria.

\section{Study Design- Prospective Study}

\section{Study Place and Participants}

The present study was carried out on patients admitted in orthopaedic ward of Shyam Shah Medical College and associated Sanjay Gandhi Memorial Hospital, Rewa (M.P.) during the 2-year period from October 2013 to September 2015.

\section{Inclusion Criteria}

1. Patients with proximal tibia fractures with or without metaphyseal extension.

2. Patients in the age group of $18-60$ yrs.

3. All the patients with acute and sub-acute trauma of less than 2 weeks.

\section{Exclusion Criteria}

1. Patients out of study age group.

2. Patients not giving consent for the operative procedure.

3. Open fractures Grade $3 \mathrm{~b}$ and 3c.

4. Avulsion fractures around knee joint.

5. Patients with neurovascular compromise.

On admission, demographic data was recorded. Thorough history and clinical examination was done. We assessed the extent of soft tissue injury and other associated injuries.

Routine preoperative protocol as per our hospital guidelines were done, and further investigations were carried out depending on the general condition of the patient. X-ray and CT scan were obtained in all the cases.

Of the total 40 patients studied, all underwent fracture fixation under spinal anaesthesia by minimally invasive percutaneous plate technique (MIPPO).

In the study, timing of surgery depended on the soft tissue conditions, and the surgery was delayed if the fractures had established severe swelling and skin blisters.

\section{Procedure}

Under spinal anaesthesia, patients were placed on radiolucent table. The ipsilateral iliac crest and entire lower limb was prepared and draped in the usual sterile fashion.

Under image intensifier, temporary reduction of fracture using large towel clip was performed by closed method. A limited surgical approach was made over the lateral aspect of proximal tibia. Before placing the plate, the fracture was reduced and evaluated with image intensifier. A submuscular plane was developed under the anterior compartment muscles and the Locking Compression Plate of adequate length was slid under the muscles. Based on the fracture pattern (Schatzker type), the fracture was reduced and tibial articular congruity maintained. This was confirmed by fluoroscopy. After evaluating the location of plate both clinically and with the fluoroscopy in both coronal and sagittal planes, the plate was secured to the bone with 1 - 2 temporary K-wires. Through the slot given in the locking compression plate, buttressing of the plate was done with 3 - 4 locking head screws of appropriate length using the drill sleeves. Distal screws were applied using either cortical or locking head screws by percutaneous technique.

Iliac bone grafting was performed in six cases where there was metaphyseal defect. Final fracture reduction and plate positions were confirmed with image intensifier. Wound was closed in layers. Sterile dressing was done. The average time of surgery was 80 minutes and the average blood loss during the surgery was $<150 \mathrm{~mL}$. Wound dressing was done on the 2nd and 7th post-operative day. Sutures were removed on the 12 th post-operative day.

\section{Post-Operative Care}

In the immediate post-operative period, care was given to the general condition and fluid balance. Adequate antibiotics were given as per the hospital protocol for orthopaedic surgeries. Oral analgesia was started from the $2^{\text {nd }}$ post-operative day till adequate pain relief ensured. This also helped us to mobilise the patient faster.

\section{Rehabilitation}

Rehabilitation was started from the $2^{\text {nd }}$ post-operative day, static quadriceps exercises was started immediately following surgery, as the patient was able to bear pain. All patients were started on non-weight bearing ambulation from the $3^{\text {rd }}$ postoperative day till 6 weeks. External support was given in the form of long knee brace, which was removed intermittently for range of motion exercises. Sutures were removed on the 12th post-operative day. Partial weight bearing ambulation was begun after first post-operative visit, confirming the beginning of healing process on radiograph. Complete weight bearing was allowed after confirmation of fracture union by Radiology and adequate pain relief.

\section{Followup}

The first followup was at 6 weeks and later on patients were followed up at regular intervals of 6 weeks, till fracture union was complete.

\section{During the Followup}

1. The course of fracture healing was documented radiologically.

2. Evaluation was done for any loss of reduction.

3. Amount of pain relief after surgery.

4. Assessment of improvement in knee range of movements postoperatively.

5. Assessment and analysis of any complications observed.

All patients were followed up for an average of 1 year after surgery till fracture union was complete, both radiologically and clinically. 


\section{RESULTS}

A total of 40 patients with proximal tibial fractures who were treated with MIPPO technique were studied. Most of the patients belonged to the age group of $20-40$ years (70\%), which was the highly active and mobile age, thereby being prone to road traffic accidents.

Out of the total 40 patients, only $5(13 \%)$ of them were females and 35 (87\%) were males.

\begin{tabular}{|c|c|c|}
\hline $\begin{array}{c}\text { Age Group } \\
\text { (In Years) }\end{array}$ & $\begin{array}{c}\text { Number of } \\
\text { Patients }\end{array}$ & Percentage \\
\hline $20-30$ & 13 & 32.5 \\
\hline $31-40$ & 15 & 37.5 \\
\hline $41-50$ & 5 & 12.5 \\
\hline $51-60$ & 4 & 10 \\
\hline$>60$ & 3 & 7.5 \\
\hline
\end{tabular}

Unilateral fractures were more common than bilateral and the right side showed a slight predominance over the left.

\begin{tabular}{|c|c|c|c|}
\hline Side & Right & Left & Bilateral \\
\hline Number of Cases & $21 \quad 18$ & 1 \\
\hline \multicolumn{2}{|c|}{ Side of Fracture } \\
\hline
\end{tabular}

Most of the fractures were of the type 3 and type 4 of Schatzker's classifications, which were usually associated with high velocity RTA.

\begin{tabular}{|c|c|c|}
\hline Type of Fracture (Schatzker's Type) & No. of Patients & Percentage \\
\hline 1 & 5 & 12.5 \\
\hline 2 & 5 & 12.5 \\
\hline 3 & 8 & 20 \\
\hline 4 & 9 & 15 \\
\hline 5 & 6 & 17.5 \\
\hline 6 & 7 & \\
\hline \multicolumn{2}{|r|}{ Type of Fracture (Schatzker's Classification) } \\
\hline
\end{tabular}

Out of 40 patients, most common mode of trauma was RTA followed by fall from height and assault.

\begin{tabular}{|c|c|c|}
\hline Mode of Trauma & No. of Patients & Percentage \\
\hline RTA & 32 & 80 \\
\hline Fall & 5 & 12.5 \\
\hline Assault & 2 & 2.5 \\
\hline Others & 1 & \\
\hline \multicolumn{2}{|c|}{ Mode of Trauma } \\
\hline
\end{tabular}

Out of the complications observed, one patient had infection which was immediate post-operative in a patient with compound fracture, which was treated with thorough debridement and antibiotics. Two patients had joint stiffness, persistent pain and reduced range of motion owing to excessive articular surface comminution. One patient has implant failure due to early full weight bearing managed with extraction of broken implant and replating. One patient has non-union, which was treated with bone grafting at later stage.

\begin{tabular}{|c|c|c|}
\hline Complication & No. of Cases & Percentage \\
\hline Infection & 1 & 2.5 \\
\hline Joint Stiffness & 2 & 2.5 \\
\hline Implant Failure & 1 & 2.5 \\
\hline Non-Union & 1 & \multicolumn{2}{c|}{} \\
\hline \multicolumn{2}{|c|}{ Complications } \\
\hline
\end{tabular}


Out of 40 fractures treated 23 fractures gave excellent result, 12 fractures healed with good results. Only 3 of the patients showed fair results and 2 had poor result.
Clinical and radiological outcomes based on modified Rasmussen criteria.

\begin{tabular}{|c|c|c|}
\hline Clinical Results & Number of Fractures & Percentage \\
\hline Excellent & 23 & 57.5 \\
\hline Good & 12 & 30 \\
\hline Fair & 3 & 7.5 \\
\hline Poor & 2 & 5 \\
\hline Total & $\mathbf{4 0}$ & $\mathbf{1 0 0}$ \\
\hline
\end{tabular}

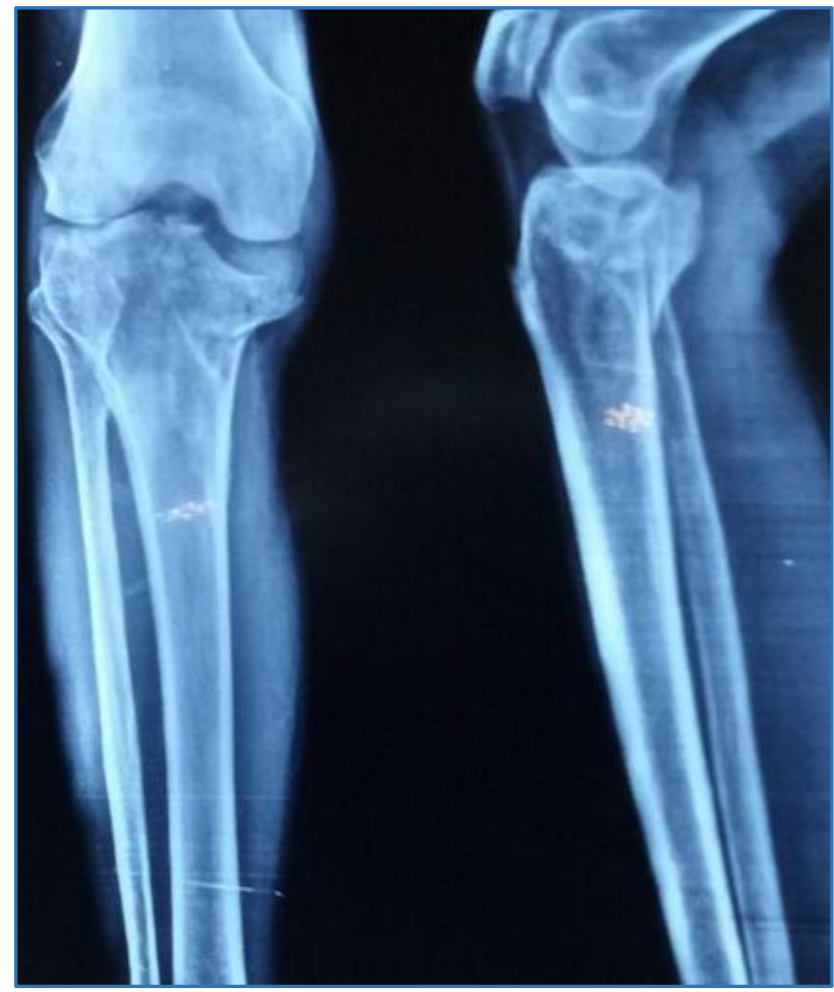

Pre-Op X-Ray

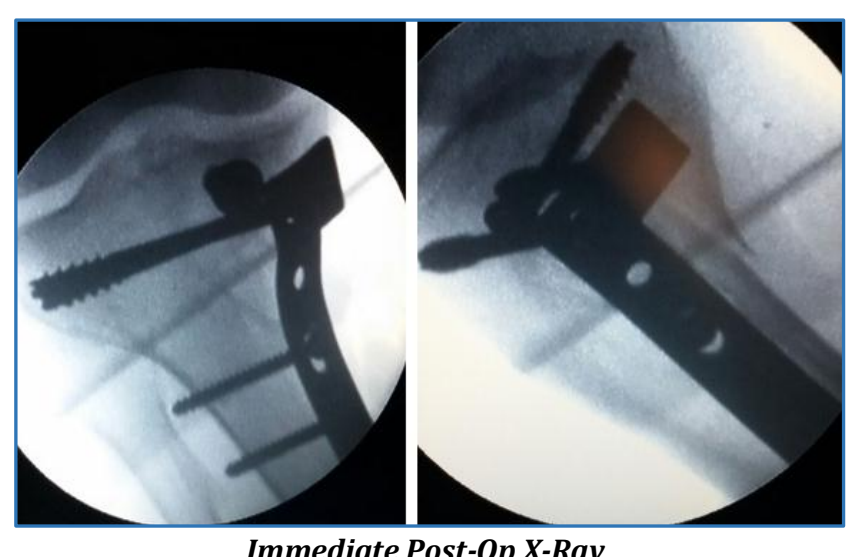

Immediate Post-Op X-Ray

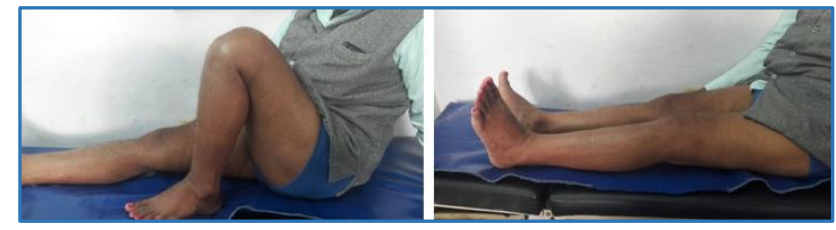

Clinical Photograph after 8 Weeks

\section{DISCUSSION}

Tibial plateau fractures, one of the commonest intraarticular fractures are major traumatic injury occurring due to road traffic accidents, fall from height, violence, etc. It is sometimes associated with other bony or soft tissue injuries. Any fracture around the joint (especially weight bearing joint in the lower limb) is of paramount importance, as it would result in significant morbidity and quality of life. Hence, the treatment of upper tibial fractures with intraarticular extension has become a challenge for orthopaedic surgeons.

Moreover, the management of high energy proximal tibia fractures is a challenging task for the surgeon, as they are often associated with a number of complications. $4,5,6,7$

Of late with the better understanding of peculiarities in proximal tibial fracture, fracture healing and complications associated with them, there has been research in better tissue friendly approaches (MIPPO) and development of better technically mature implant systems (LCP) for fracture fixation, which are showing promising results by early restoration of strength at fracture site and function of knee joint. MIPPO enables indirect fracture reduction and percutaneous submuscular implant placement. ${ }^{8}$

Favourable outcome is not due to MIPPO, but due to less extensive dissection of soft-tissue envelope and devitalisation of fracture fragments.

The patients with fracture in our study occurred between the age of 20 to 60 years with maximum incidence involving the productive age group of 20 - 50 years (82.5\%). This was in accordance with a study by P. A. Cole et al in 2004 who also found the majority of patients in productive age with an average of 45 years, and with the study of Ricci and Stannard with average of 53 years and 38 years respectively.9,10,11

In our study, the commonest mode of injury was road traffic accident (80\%), the other being fall (12.5\%). In another Indian study by Sharma et al, similar results were found where RTA was the most common cause of these fractures. ${ }^{12}$ This is due to the high probability of injuries occurring in this age group due to RTA. 
In our series majority of the patients were males $87 \%$, which can be attributed to our Indian setup where the female population largely work indoor and do not travel much.

There was not much difference in the laterality of the fracture. The right tibia was affected in 52.5\%, left tibia in $45 \%$ of cases and bilateral in $2.5 \%$ of cases.

In this study, out of the 40 fractures most of them fell into Schatzker's type 3, 4 and type 5 classification of proximal tibial fractures. In the study by Sharma et al type 5 and 6 were more common as was seen in another study by Marsh et al,13 while in a study by Raza et al, type 3 and type 2 were found to be the predominant ones. 14

The average time for union of fractures was 21 weeks in our series ranging from 16 to 24 weeks. An average of $110^{\circ}$ knee joint range of motion was achieved. Soft tissue damage, intraarticular fracture, severity of fracture and physiotherapy determined knee range of motion. Both Cole et al and Egol et al reported similar range of movement results when using locked plate for these fractures (range 0 to $122^{\circ}$ and 0 to $109^{\circ}$ respectively).9,15

Amongst the complications observed, 1 patient (2.5\%) developed infection within 2 weeks postoperatively, which was comparable to the studies conducted by Egol et al ${ }^{15}$ who reported no infection, Stannard et al ${ }^{11}$ reported $5.9 \%$ rate of infection and Cole et $\mathrm{al}^{9}$ with $4 \%$ rate of infection.

We had excellent clinical and radiological outcome in $57.5 \%$ of the cases and in $30 \%$ of the cases it was good. Only in $2(5 \%)$ of the patients, the result was poor. Reddy et al reported an excellent result in $86.7 \%$ of the cases and $13.3 \%$ had good results, while in a study by Rohra et al $85.29 \%$ of the patients had excellent and $14.71 \%$ had good results. ${ }^{16}$ Simialr results were observed by Yu et al, Prasad et al, Zhang et al and Oh et al. ${ }^{17-21}$

\section{CONCLUSION}

The surgical managements of tibial plateau fractures is an orthopaedic challenge and needs a comprehensive understanding of fracture, soft tissue, time interval from injury to surgery and post-operative rehabilitation. Modalities like LCP in MIPPO and bone grafting can give excellent results in desirable patients, but requires an optimum learning curve. The functional outcome is inversely proportional to the severity of the fracture. Bicondylar fractures, compound fractures, advanced age are less likely to have favourable results as compared to unicondylar fractures, closed fractures and younger age group patients. Infection rates are minimal in MIPPO, as there is minimal soft tissue injury and preservation of vascularity and fracture haematoma. Malunion is one of the complications and therefore careful attention has to be given to overcome this by achieving anatomical reduction and stable implant fixation.

\section{REFERENCES}

[1] DeCoster TA, Nepola JV, El-Khoury GY. Cast brace treatment of proximal tibia fractures. A ten year follows up study. Clin Orthop Relat Res 1988;231:196204.

[2] Apley AG. Fractures of tibial plateau. Clin Orthop North Am 1979;10(1):61-74.
[3] Sirkin MS, Bono CM, Reilly MC, et al. Percutaneous methods of tibial plateau fixation. Clin Orthop 2000;375:60-8.

[4] Lansinger O, Bergman B, Korner L, et al. Tibial condylar fractures. A twentyyear follow-up. J Bone Joint Surg Am 1986;68(1):13-9.

[5] Young MJ, Barrack RL. Complications of internal fixation of tibial plateau fractures. Orthop Rev 1994;23(2):149-54.

[6] Schatzker J, McBroom R, Bruce D. The tibial plateau fracture. The toronto experience 1968-1975. Clin Orthop 1979;138:94-104.

[7] Papagelopoulos PJ, Partsinevelos AA, Themistocleous GS, et al. Complications after tibia plateau fracture surgery. Injury 2006;37(6):475-84.

[8] Cole PA, Zlowodzki M, Kregor PJ. Less invasive stabilization system (LISS) for fractures of the proximal tibia: indications, surgical technique and preliminary results of the UMC clinical trial. Injury 2003;34(Suppl 1):A16-29.

[9] Cole PA, Zlowodzki M, Kergor PJ. Treatment of proximal tibia fracture using the less invasive stabilization system: surgical experience and early clinical results in 77 fractures. J Orthop 2004;18(8):528-35.

[10] Ricci WM, Rudzki JR, Borrelli J. Treatment of complex proximal tibial fracture with the less invasive skeletal stabilization system. J Orthop Trauma 2004;18(8):5217.

[11] Stannard JP, Wilson TC, Volgas DA, et al. Fracture stabilization of proximal tibial fractures with the proximal tibial LISS: early experience in Birmingham, Alabama (USA). Injury 2003;34(Suppl 1):A36-42.

[12] Sharma R, Kapila R, Singh BP, et al. Traditional buttress plating v/s MIPO in management of proximal tibial fractures - a clinical study. Pb Journal of Orthopaedics 2013;14(1):11-6.

[13] Marsh JL, Smith ST, Do TT. External fixation and limited internal fixation for complex fractures of the tibial plateau. J Bone Joint Surg Am 1995;77(5):661-73.

[14] Raza H, Hashmi P, Abbas K, et al. Minimally invasive plate osteosynthesis for tibial plateau fractures. Journal of Orthopaedic Surgery 2012;20(1):42-7.

[15] Egol KA, Su E, Tejwani NC, et al. Treamtent of complex tibial plateau fractures using the less invasive stabilization system plate: clinical experience and a laboratory comparison with double plating. J trauma 2004;57(2):340-6.

[16] Reddy JPK, Nazeer BS, Arun HS, et al. Study of surgical management of proximal tibial fractures using locking compression plate. IJBAR 2016;7(3):123-7.

[17] Rohra N, Suri HS, Gangrade K. Functional and radiological outcome of schatzker type $\mathrm{V}$ and $\mathrm{VI}$ tibial plateau fracture treatment with dual plates with minimum 3 years follow-up: a prospective study. J Clin Diagn Res 2016;10(5):RC05-10.

[18] Yu Z, Zheng L, Zhang Y, et al. Functional and radiological evaluations of high energy tibial plateau fractures treated with double-buttress plate fixation. Eur J Med Res 2009;14(5):200-5. 
[19] Prasad GT, Kumar TS, Kumar RK, et al. Functional outcome of schatzker type $\mathrm{V}$ and VI tibial plateau fractures treated with dual plates. Indian J Orthop 2013;47(2):188-94.

[20] Zhang Y, Fan DG, Ma BA, et al. Treatment of complicated tibial plateau fractures with dual plating via a 2-incision technique. Orthopedics 2012;35(3):e359-64.
[21] Oh CW, Oh JK, Kyung HS, et al. Double plating of unstable proximal tibial fractures using minimally invasive percutaneous osteosynthesis technique. Acta Orthop 2006;77(3):524-30. 